\title{
Repurposing of FDA Approved Drugs for the Identification of Potential Inhibitors of SARS-CoV-2 Main Protease
}

\author{
Abhik Kumar Ray ${ }^{1 \$}$, Parth Sarthi Sen Gupta ${ }^{1 \$}$, Saroj Kumar Panda ${ }^{1}$, Satyaranjan Biswal ${ }^{1}$, \\ Malay Kumar Rana ${ }^{1 *}$ \\ ${ }^{1}$ Department of Chemical Sciences, Indian Institute of Science Education and Research (IISER) \\ Berhampur, Odisha-760010, India. \\ \$Authors contributed equally
}

\section{* Corresponding Author}

Dr. Malay Kumar Rana,

Assistant Professor,

Department of Chemical Sciences,

Indian Institute of Science Education and Research (IISER) Berhampur,

Ganjam, Odisha, 760010, India

Email:mrana@iiserbpr.ac.in

Mobile: +91-680-2227753 


\begin{abstract}
COVID-19, responsible for several deaths, demands a cumulative effort of scientists worldwide to curb the pandemic. The main protease, responsible for the cleavage of the polyprotein and formation of replication complex in virus, is considered as a promising target for the development of potential inhibitors to treat the novel coronavirus. The effectiveness of FDA approved drugs targeting the main protease in previous SARS-COV (s) reported earlier indicates the chances of success for the repurposing of FDA drugs against SARS-COV-2. Therefore, in this study, molecular docking and virtual screening of FDA approved drugs, primarily of three categories: antiviral, antimalarial, and peptide, are carried out to investigate their inhibitory potential against the main protease. Virtual screening has identified 53 FDA drugs on the basis of their binding energies $(<-7.0 \mathrm{kcal} / \mathrm{mol})$, out of which the top two drugs Velpatasvir $(-9.1 \mathrm{kcal} / \mathrm{mol})$ and Glecaprevir (-9.0 kcal/mol) seem to have great promise. These drugs have a stronger affinity to the SARS-CoV-2 main protease than the crystal bound inhibitor $\alpha$-ketoamide $13 \mathrm{~B}(-6.7 \mathrm{kcal} / \mathrm{mol})$ or Indinavir $(-7.5 \mathrm{kcal} / \mathrm{mol})$ that has been proposed in a recent study as one of the best drugs for SARS-CoV-2. The in-silico efficacies of the screened drugs could be instructive for further biochemical and structural investigation for repurposing. The molecular dynamics and viral inhibition assay studies on the shortlisted drugs are underway.
\end{abstract}

Keywords: COVID-19, SARS-CoV-2, Main protease, Repurposing, Antiviral, Virtual screening

\title{
1. Introduction
}

Severe Acute Respiratory Syndrome Coronavirus 2 (SARS-CoV-2), emerged from the Wuhan city of China in late 2019, has drawn considerable attention from the scientific community worldwide, because of its severity and rapid spread of the disease (Zhu et al., 2020; Muralidharan et al., 2020; Gupta et al., 2020). An increasing number of cases and death from the coronavirus (COVID-19) worldwide certainly has an adverse impact on health and economics (Zhu et al., 2020). Thus, the identification of antiviral agents against SARS-COV-2 for the treatment of COVID-19's infection is of utmost urgency. Since the identification, development, and clinical trial in humans of any new drug takes enormous time, the repurposing of already available FDA approved drugs seems the fastest route to combat with the current novel COVID-19 pandemic. 
The main protease (Mpro), also known as 3CLpro, consists of three domains, with amino acid sequences 8-101 (Domain I), 102-184 (Domain II), and 185-306 (Domain III). Domains I and II constitute the antiparallel $\beta$ barrel that forms the substrate-binding between them and Domain III is a globular cluster that helps in dimerization of Mpro [J. Shi et al.,2006]. The loop region connects Domain II to Domain III by residues within 189-191. The protease structure has a chymotrypsinlike fold that can be described as an augmented serine-protease forms a His41-Cys145 catalytic dyad at the catalytic cleavage; other important substrate-binding residues within S1-S5 subsites are Thr25, Met49, Phe140, Leu141 Asn142, Gly143, Ser144, Cys145, His163, Met165, Glu166, His172, Gln189, and Thr190 [Jin at al.,2020 and L. Zhang et al.,2020], Figure 1.

To date, among all coronaviruses, SARS-CoV-2 is the largest in size, approx. 27-34 kb, which belongs to a family of positive-sense, single-stranded RNA viruses. Its replicase genome encodes two polyproteins, ppla and pp1ab, overlapping by ribosomal frameshifting [Zhou et al,2020 and $\mathrm{Wu}$ et al.,2020]. Proteolytic cleavage produces non-structural proteins, which form the replicase transcriptase complex. Non-structural protein 5 (nsp5) or the main protease (Mpro) exists in the polyprotein pp1a.

Among all the therapeutic targets in SARS-COV-2, Mpro is a vital as well as the best-characterized drug target for rational drug designing [Xia B et al.,2011 and Lu I-L et al.,2006]. Protease has a key role in infecting host cells [C. Steinkühler et al.,2008 \& Y. Wan et al.,2020]. It has also an important role in processing the polyproteins that are translated from the viral RNA [R. Hilgenfeld et al.,2014]. Thus, inhibiting the activity of this enzyme would block the viral replication. Moreover, since no proteases with a similar cleavage specificity are known in humans, such inhibitors are unlikely to be toxic. Therefore, the replication process of the virus can be inhibited by designing a novel inhibitor against the SARS-CoV-2 Mpro.

While drug repurposing can be realized to offer a faster solution to prevent the rapid everspreading infection of COVID-19 [T. T. Ashburn et. al.,2004 \& J. Xu et. al.,2020], the recently solved high-resolution structure of the SARS-CoV-2 Mpro in complex with a modified $\alpha$ ketoamide inhibitor ( $\alpha$-ketoamide 13B) can be used for the screening of the potential inhibitors from the existing FDA approved drugs [Linlin Zhang et al.,2020]. The location in which $\alpha$ ketoamide binds to the main protease is regarded as the binding site in the current study. Here we employ a combination of DFT, docking, and virtual screening methods for the repurposing of FDA approved drugs to identify the drug molecules that could potentially bind to the SARS-CoV-2 Main protease. The findings of this study, we believe, can provoke the designing of experiments of the 
best-screened drugs for the antiviral assay study against the novel SARS-CoV-2 and subsequently clinical trial at a rapid pace. This study has therefore been undertaken to explore the molecular interaction of Antimalarial, Protease, and Nucleoside inhibitors with Mpro through molecular docking study.

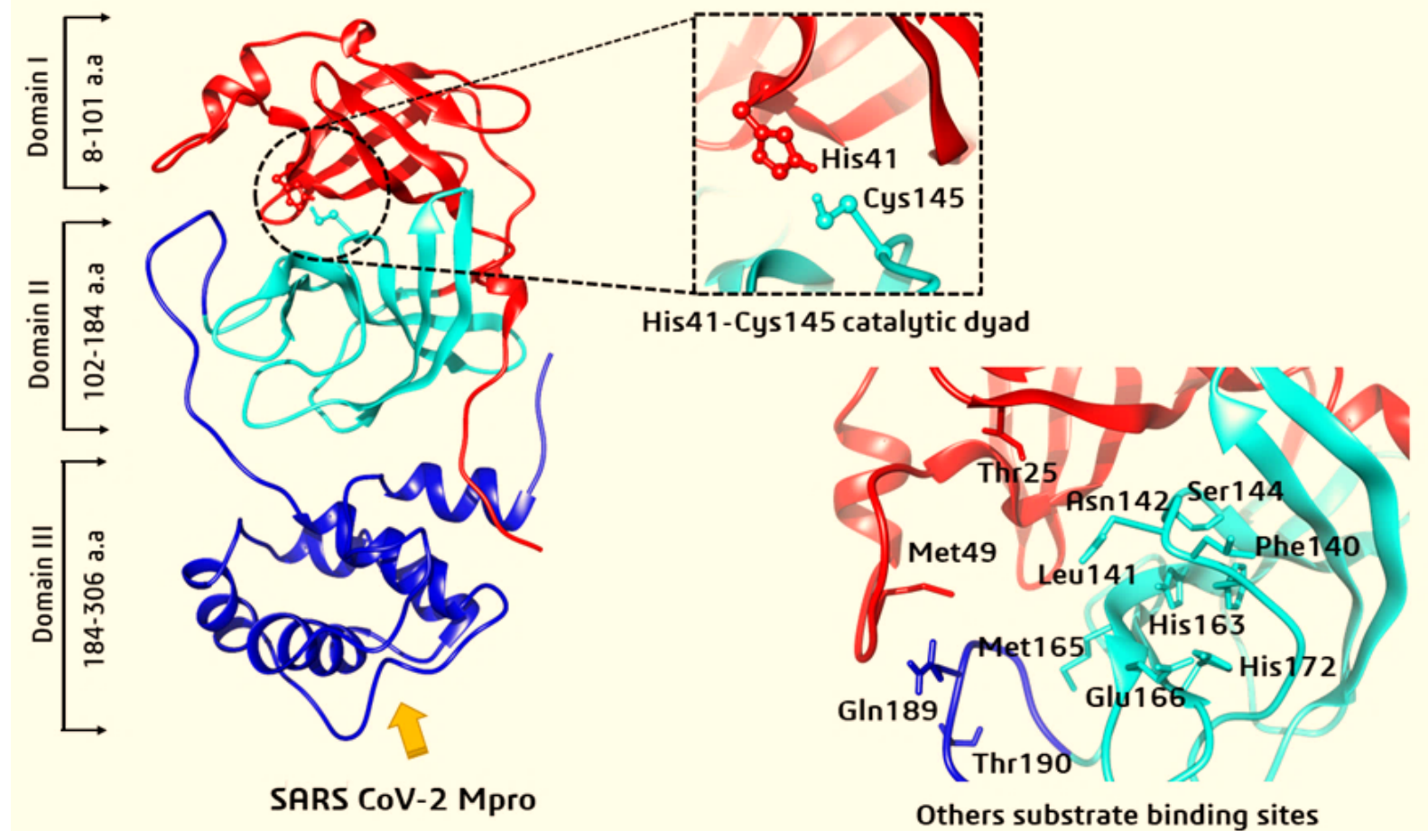

Figure 1. Three domains of the SARS-CoV-2 main protease (Mpro), with highly conserved catalytic dyad His41-Cys145 and other important catalytic residues displayed separately.

\section{Materials and Methods}

\subsection{Protein Structure Preparation}

The crystal structure of SARS-CoV-2 Mpro having PDB_ID: 6Y2F [Linlin Zhang et al.,2020], with the highest resolution of $1.95 \AA$ was retrieved from RCSB (Protein Data Bank). The missing residues Glu47, Asp48, and Gln306 were added using MODELLER [Šali \& Blundell et al.] incorporated into the Chimera UCSF and was accessed using web service [Pettersen et al.,2004].

\subsection{Binding Cleft Identification}

The interacting residues of the $\alpha$-ketoamide $13 \mathrm{~b}$ inhibitor with Mpro have been spotted in Discovery Studio visualizer and used as a binding site in the current study. The active site residues were found to be: $24-27,41,49,54,140-145,163-168,172$, and 187-192 amino acids. These residues are thoroughly conserved and make a catalytic His41-Cys145 dyad as mentioned earlier. Cysteine and Histidine are an essential amino acid, which initiate the enzyme catalytic reaction [Jin at al.,2020 and L. Zhang et al.,2020]. Additionally, there was a substrate-binding subsite 
positioned in the active site groove of the protease. The specific subsite residues located in the enzyme active site are named as S1 and S2 (buried subsites), S3, S4, and S5 (shallow subsites) depending on their relative positions to the cleavage site [Jin et al.,2020]. In the Mpro active site region of SARS-CoV-2, the S1 subsite is contributed by Phe140, His163, Glu166, Cys145, Gly143, His172, which also serve as the oxyanion (or hydroxyl group) hole of serine protease [Linlin Zhang et al.,2020]. The residues Cys145, His41, and Thr25 are located at the S2 position, amino acids in this position are involved in hydrophobic and electrostatic interactions. The shallow subsites S3S5 contain Met49, His41, Met165, Glu166, Pro168, and Gln189 amino acid residues (Linlin Zhang et al.,2020). Structural details and interactions are shown in Figure 1.

\subsection{Protein and Ligand preparation}

All available FDA approved antiviral, antimalarial, and protease inhibitor drugs (total 200) were retrieved from DrugBank5.0 [Wishart DS et al.,2018] and SuperDrug2 [Vishal B Siramshetty et al.,2018] to prepare a combinatorial drug library for screening. Mpro and ligands (FDA approved drugs) were prepared for molecular docking by adding missing hydrogens and the Gasteiger charges to atoms using Autodock tools [Morris et al.,2009].

\subsection{Molecular docking}

Docking study was performed by AutoDock 4.2, AutoGrid and Vina [Trott O et al., 2010], which use a Lamarckian genetic algorithm (GA) in combination with grid-based energy estimation incorporated in PyRx [Dallakyan et al., 2015]. After molecular docking and initial screening, the screened FDA approved drugs were optimized with Gaussian 16 [M. J. Frisch et al.,2016] by the semiempirical PM6 method to improve the screening and docking scores of the drugs. This was repeated again by switching over to DFT B3LYP/6-311G (d, p) based geometry optimization followed by screening. In this manner, docking and re-docking were repeatedly performed between Mpro and the drug molecules optimized at different levels (semiempirical, DFT, etc.) to screen them out. In the docked configurations, different molecular interactions prevail such as the conventional hydrogen bond, $\pi$-sulfur, $\pi$-sigma, $\pi$-anion, $\pi$-alkyl, and Alkyl.

\section{Results and Discussion}

\subsection{Molecular docking and binding mode analysis}

All the candidates in the drug library prepared were docked at the same active site region where the ligand $\alpha$-ketoamide $13 \mathrm{~b}$ was co-crystallized with SARS-CoV-2 Mpro. 
Recently, Chang et al. reported Indinavir and Remdesivir as the best drug candidates against COVID-19 from the screening of FDA approved drugs for repurposing (Chang et al., 2020). Since Remdesivir is an RNA dependent RNA polymerase (RdRP) inhibitor, we have considered Indinavir (protease inhibitor) as a reference drug for comparison with our screened drugs against the main protease. Table 1 lists out the best screened FDA approved drugs from this study having the binding energy or docking score $\leq-9.0 \mathrm{kcal} / \mathrm{mol}$ along with a reference drug Indinavir and the co-crystallized ligand $\alpha$-ketoamide $13 \mathrm{~b}$, which have been considered for further analyses in this study. Table S1 contains all the FDA drugs with binding energies $\leq-7.0 \mathrm{kcal} / \mathrm{mol}$, a total number of 53 drugs.

Table 1: A list of the best screened FDA approved drugs, a reference drug (Indinavir), and the co-crystallized ligand with their respective binding energy with Mpro.

\begin{tabular}{|l|l|l|}
\hline S. No. & Repurpose FDA Approved Drugs Affinity & $\begin{array}{l}\text { Binding } \\
(\mathbf{k c a l} / \mathbf{m o l})\end{array}$ \\
\hline 1 & Velpatasvir & -9.1 \\
\hline 2 & Glecaprevir & -9.0 \\
\hline 3 & Indinavir & -7.5 \\
\hline 4 & $\alpha$-ketoamide 13b (co-crystallized ligand) & -6.7 \\
\hline
\end{tabular}

Compared to the $\alpha$-ketoamide $13 \mathrm{~b}$ compound as reported in Ref. [Linlin Zhang et al.], notably, the top 2 compounds in the list: Velpatasvir and Glecaprevir have very stronger affinities to the protein target SARS-CoV-2 Mpro of $-9.1 \mathrm{kcal} / \mathrm{mol}$ and $-9.0 \mathrm{kcal} / \mathrm{mol}$, respectively. Velpatasvir is an antiviral agent and NSP5A inhibitor [Ascher DB et al.,2014] used to treat chronic liver infection in the Hepatitis $\mathrm{C}$ virus [Lee $\mathrm{R}$ et al.,2017]. NSP5A is a viral protein that plays a key role in the replication of the Hepatitis $\mathrm{C}$ virus, assembly, and modulation of the host immune response [Mogalian E et al.,2017]. Likewise, Glecaprevir acts as a protease inhibitor of NS3/4A Hepatitis $\mathrm{C}$ virus by hijacking the viral replication machinery.

The interacting residues of Velpatasvir with the main protease are shown in Figure 2. 


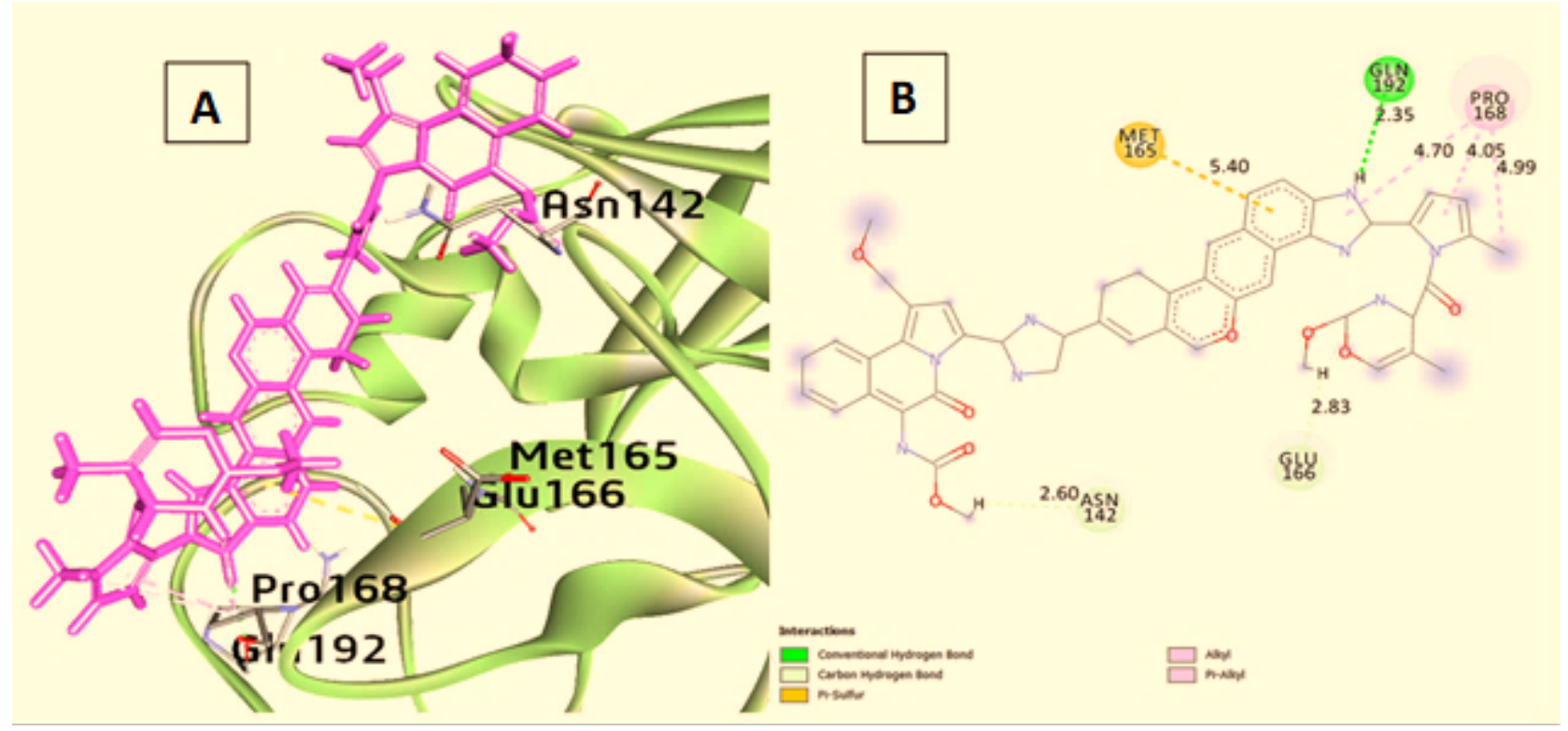

Figure 2: The (A) 3D and (B) 2D diagrams depicting residues contributed majorly to the interaction between Velpatasvir and the main protease.

The amide hydrogen ( ${ }^{\mathrm{H}-\mathrm{N}}$ ) of Velpatasvir forms a conventional hydrogen bond (h-bond) with the oxygen of Gln192 residue with $\mathrm{NH} \cdots \mathrm{O}$ within a distance of $2.35 \AA$. Asn142 and Glu166 amino acid residues are involved in carbon-hydrogen bond formation with the Velpatasvir within a distance of $2.60 \AA$ and $2.83 \AA$ respectively. Met165 residue forms a $\pi$-sulfur bond with Velpatasvir. Pro168 amino acid residue is also involved in $\pi$-alkyl interaction with Velpatasvir within the proximity of $4.05 \AA$ and $4.70 \AA$. These interactions give rise to $-9.1 \mathrm{kcal} / \mathrm{mol}$ energy as mentioned before.

Glecaprevir binds strongly to the target site of the main protease with four conventional h-bonds

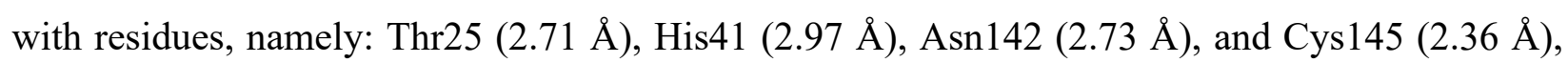
please see Figures 3A and B. Apart from these h-bonds, there exists one carbon-hydrogen bond interaction with His41(3.74 $\AA$ ). There is $-9.0 \mathrm{kcal} / \mathrm{mol}$ interaction energy between Glecaprevir and the main protease as shown in Table 1. Glu166 side chain residue is also interacting in close proximity with two aromatic rings within $3.23 \AA$ and $3.68 \AA$ distances. Moreover, residues like Pro168 and Thr26 interact with an alkyl group and the halogen atom of Glecaprevir as seen in Figure 3. For all drugs listed in Table 1, which includes two shortlisted FDA approved drugs, a reference drug, and the co-crystallized ligand, the details of various interactions present are provided in Table S1. 


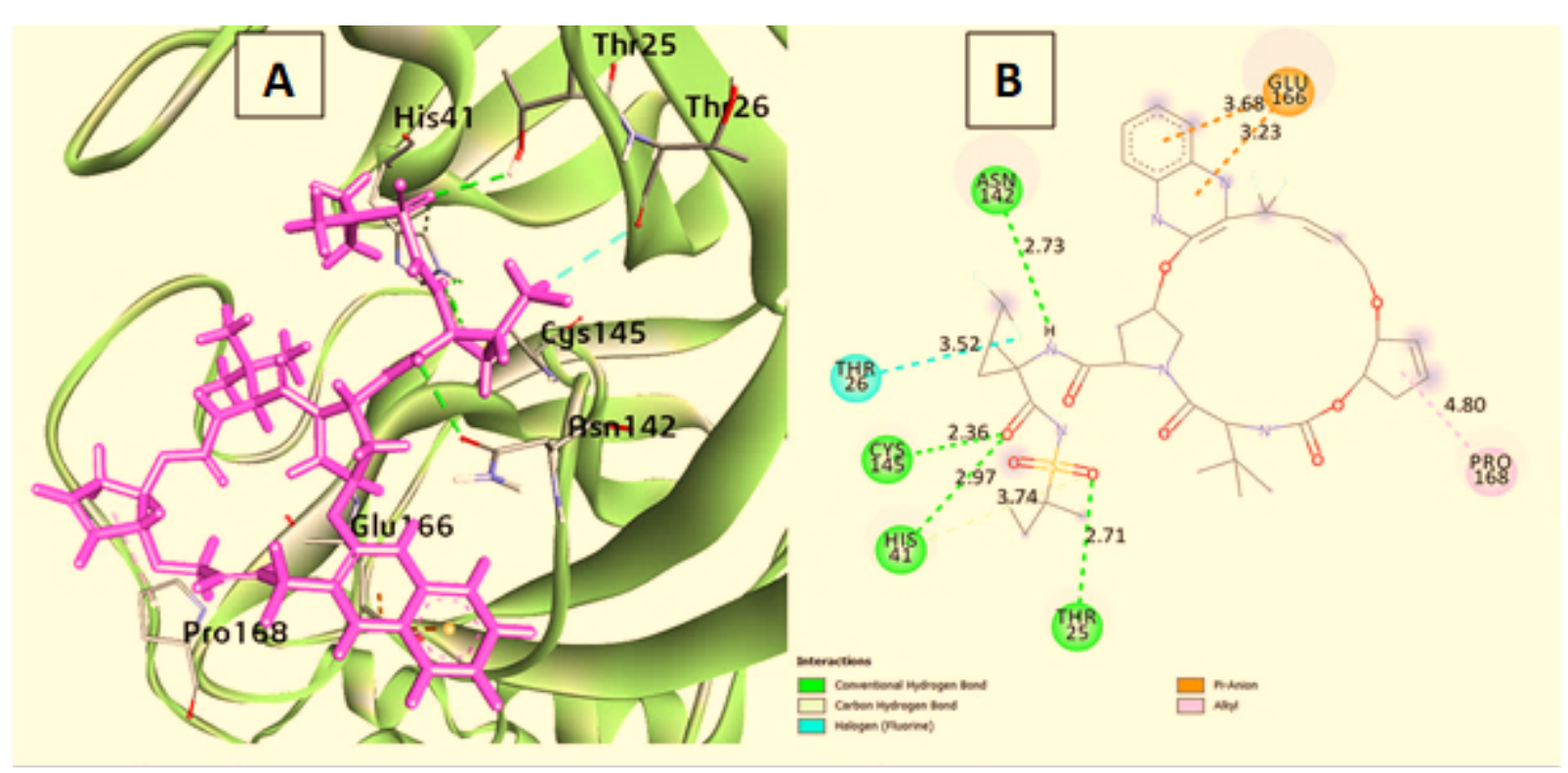

Figure 3: The (A) 3D and (B) 2D diagrams depicting residues contributed majorly to the interaction between Glecaprevir and the main protease.

Figure 4 shows the interacting residues of the main protease with the reference FDA drug Indinavir. Indinavir interacts with the main protease to form three h-bonds involving GLU166, HIS164, and THR45 within $2.26 \AA, 2.20 \AA$, and $2.15 \AA$ distances, respectively. Residues involved in $\pi$-interactions are LEU141 and MET165, which are situated $3.82 \AA$ and $5.13 \AA$, respectively, vicinal to the nearest interacting sites of Indinavir. Altogether, these interactions result in -7.5 $\mathrm{kcal} / \mathrm{mol}$ binding energy between Indinavir and the main protease given in Table 1 as mentioned before. 


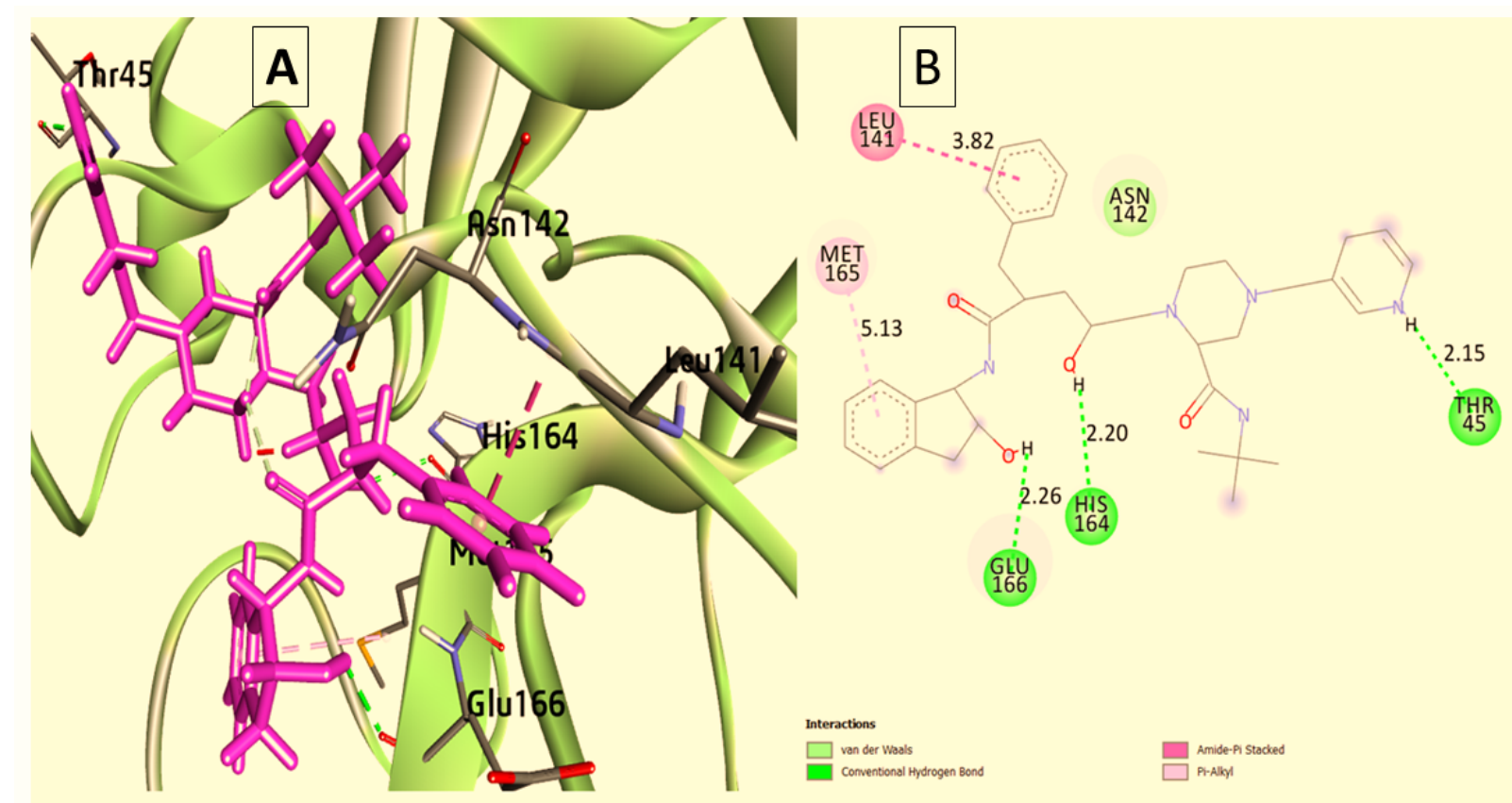

Figure 4: The (A) 3D and (B) 2D diagrams depicting residues contributed majorly to the interaction between Indinavir and the main protease.

Interestingly, the FDA approved drug Velpatasvir having the best docking score seems to possess a less number of interactions than Glecaprevir and others (Tables 1 and S2). What are the factors responsible for the lowest binding energy of Velpatasvir than others? After careful observation, it is recognized that the involvement of a large number of amino acid residues participating in the van der Waals interaction and their additive effect might be the reason of the lowest binding energy. Molecular dynamics simulation and free energy calculation may further insight into this and validate the screening results.

\section{Conclusion}

The present study deals with the screening of existing antiviral, antimalarial, and protease inhibitor FDA approved drugs against a crucial target of SARS-COV-2, the main protease, to find a faster remedy to the ever-spreading infection of COVID-19. Molecular docking and virtual screening of 200 FDA approved drugs revealed Velpatasvir and Glecaprevir could be the best choices to treat COVID-19 because of their strongest binding affinities around $-9.0 \mathrm{kcal} / \mathrm{mol}$ with the SARS-COV2 target. The FDA approved drug Indinavir being reported recently as one of the best inhibitors of SARS-COV-2, we have compared Indinavir with our screened-out drugs which outperform the former. To further validate the screening results, molecular dynamics and free energy calculation are underway. Post-molecular dynamics simulation, Velpatasvir and Glecaprevir will undergo antiviral assay study here against the main protease of SARS-CoV-2 (COVID-19) that will be 
decisive for the next clinical trial step. The structural insights, key interacting residues, and the binding mechanisms of the screened drugs would further help in designing a better inhibitor of the main protease.

\section{Acknowledgements}

The authors acknowledge IISER Berhampur for computational support. A.K.R. and P.S.S.G also sincerely acknowledge IISER Berhampur for providing them the Project Fellow position and Institute Postdoc Fellowship, respectively, to carry out this work.

\section{Conflict of interest}

The authors report no conflicts of interest.

\section{References}

Ascher DB, Wielens J, Nero TL, Doughty L, Morton CJ, Parker MW: Potent hepatitis C inhibitors bind directly to NS5A and reduce its affinity for RNA. Sci Rep. 2014 Apr 23; 4:4765. doi: 10.1038/srep04765.

Cada DJ, Kim AP, Baker DE. Elbasvir/Grazoprevir. Hosp Pharm. 2016;51(8):665-686. doi:10.1310/hpj5108-665.

Chang, Y.; Tung, Y.; Lee, K.; Chen, T.; Hsiao, Y.; Chang, H.; Hsieh, T.; Su, C.; Wang, S.; Yu, J.; Shih, S.; Lin, Y.; Lin, Y.; Tu, Y.E.; Hsu, C.; Juan, H.; Tung, C.; Chen, C. Potential Therapeutic Agents for COVID-19 Based on the Analysis of Protease and RNA Polymerase Docking. Preprints 2020, 2020020242 (doi: 10.20944/preprints202002.0242.v2).

Christian Steinkühler. Viral Proteases. Encyclopedia of Molecular Pharmacology, 2008 Edition. Springerlink.

Dallakyan, Sargis \& Olson, Arthur. (2015). Small-Molecule Library Screening by Docking with PyRx. Methods in molecular biology (Clifton, N.J.). 1263. 243-250. 10.1007/978-1-4939-2269$7 \_19$.

Gaussian 16, Revision C.01, M. J. Frisch, G. W. Trucks, H. B. Schlegel, G. E. Scuseria, M. A. Robb, J. R. Cheeseman, G. Scalmani, V. Barone, G. A. Petersson, H. Nakatsuji, X. Li, M. Caricato, A. V. Marenich, J. Bloino, B. G. Janesko, R. Gomperts, B. Mennucci, H. P. Hratchian, J. V. Ortiz, A. F. Izmaylov, J. L. Sonnenberg, D. Williams-Young, F. Ding, F. Lipparini, F. Egidi, J. Goings, B. Peng, A. Petrone, T. Henderson, D. Ranasinghe, V. G. Zakrzewski, J. Gao, N. Rega, G. Zheng, W. Liang, M. Hada, M. Ehara, K. Toyota, R. Fukuda, J. Hasegawa, M. Ishida, T. Nakajima, Y. Honda, O. Kitao, H. Nakai, T. Vreven, K. Throssell, J. A. Montgomery, Jr., J. E. Peralta, F. Ogliaro, M. J. Bearpark, J. J. Heyd, E. N. Brothers, K. N. Kudin, V. N. Staroverov, T. A. Keith, R. Kobayashi, J. Normand, K. Raghavachari, A. P. Rendell, J. C. Burant, S. S. Iyengar, J. Tomasi, M. 
Cossi, J. M. Millam, M. Klene, C. Adamo, R. Cammi, J. W. Ochterski, R. L. Martin, K. Morokuma, O. Farkas, J. B. Foresman, and D. J. Fox, Gaussian, Inc., Wallingford CT, 2016.

Gupta MK, Vemula S, Donde R, Gouda G, Behera L, Vadde R. In-silico approaches to detect inhibitors of the human severe acute respiratory syndrome coronavirus envelope protein ion channel. Journal of Biomolecular Structure and Dynamics. 2020 Apr 2(just-accepted):1-7. https://doi.org/10.1080/07391102.2020.1751300

J. Shi, J. Song, The catalysis of the SARS 3C-like protease is under extensive regulation by its extra domain. FEBS J. 273, 1035-1045 (2006). doi:10.1111/j.17424658.2006.05130.xpmid:16478476.

Jin, Z., Du, X., Xu, Y., Deng, Y., Liu, M., Zhao, Y., \& Zhang, B. (2020). Structure of Mpro from COVID-19 virus and discovery of its inhibitors. bioRxiv.

J. Xu, P.-Y. Shi, H. Li \& J. Zhou, Broad Spectrum Antiviral Agent Niclosamide and ItsTherapeutic Potential, ACS infectious diseases, (2020) 10.1021/acsinfecdis.0c00052.

Lee R, Kottilil S, Wilson E. Sofosbuvir/velpatasvir: a pangenotypic drug to simplify HCV therapy. Hepatology International. 2017 Mar;11(2):161-170. DOI: 10.1007/s12072-016-9776-8.

Lu I-L, Mahindroo N, Liang P-H, Peng Y-H, Kuo C-J, Tsai K-C, et al. Structure-based drug design and structural biology study of novel nonpeptide inhibitors of severe acute respiratory syndrome coronavirus main protease. Journal of medicinal chemistry. 2006;49:5154-61.

L. Zhang, D. Lin, Y. Kusov, Y. Nian, Q. Ma, J. Wang, A. von Brunn, P. Leyssen, K.Lanko, J. Neyts, A. de Wilde, E. J. Snijder, H. Liu, R. Hilgenfeld, $\alpha$-Ketoamides asbroad-spectrum inhibitors of coronavirus and enterovirus replication: Structurebased design, synthesis, and activity assessment. J. Med. Chem.acs.jmedchem.9b01828 (2020). doi:10.1021/acs.jmedchem.9b01828 Medline.

Mogalian E, German P, Kearney BP, Yang CY, Brainard D, Link J, McNally J, Han L, Ling J, Mathias A: Preclinical Pharmacokinetics and First-in-Human Pharmacokinetics, Safety, and Tolerability of Velpatasvir, a Pangenotypic Hepatitis C Virus NS5A Inhibitor, in Healthy Subjects. Antimicrobe Agents Chemother. 2017 Apr 24;61(5). pii: e02084-16. doi: 10.1128/AAC.02084-16. Print 2017 May. [PubMed:28193657].

Morris, G. M., Huey, R., Lindstrom, W., Sanner, M. F., Belew, R. K., Goodsell, D. S. and Olson, A. J. (2009) Autodock4 and AutoDockTools4: automated docking with selective receptor flexibility. J. Computational Chemistry 2009, 16: 2785-91.

M.J. Abraham, T. Murtola, R. Schulz, S. Páll, J.C. Smith, B. Hess, and E. Lindahl, "GROMACS: High performance molecular simulations through multi-level parallelism from laptops to supercomputers," SoftwareX, 1-2 19-25 (2015).

Muralidharan N, Sakthivel R, Velmurugan D, Gromiha MM. Computational studies of drug repurposing and synergism of lopinavir, oseltamivir and ritonavir binding with SARS-CoV-2 Protease against COVID-19. Journal of Biomolecular Structure and Dynamics. 2020 Apr 4(justaccepted):1-7. https://doi.org/10.1080/07391102.2020.1752802

R. Hilgenfeld, From SARS to MERS: Crystallographic studies on coronaviral proteases enable antiviral drug design. FEBS J. 281, 4085-4096 (2014). doi:10.1111/febs.12936pmid:25039866. 
Salam, Kazi Abdus, and Nobuyoshi Akimitsu. "Hepatitis C virus NS3 inhibitors: current and future perspectives." BioMed research international 2013 (2013).

T. T. Ashburn \& K. B. Thor, Drug repositioning: identifying and developing new uses forexisting drugs, Nature reviews. Drug discovery, 3(8) (2004) 673-683.

Trott O, Olson AJ (2010) AutoDock Vina: improving the speed and accuracy of docking with a new scoring function, efficient optimization, and multithreading. J Comput Chem 31:455-461

UCSF Chimera--a visualization system for exploratory research and analysis. Pettersen EF, Goddard TD, Huang CC, Couch GS, Greenblatt DM, Meng EC, Ferrin TE. J Comput Chem. 2004 Oct;25(13):1605-12.

Vishal B Siramshetty, Oliver Andreas Eckert, Björn-Oliver Gohlke, Andrean Goede, Qiaofeng Chen, Prashanth Devarakonda, Saskia Preissner, Robert Preissner; SuperDRUG2: a one stop resource for approved/marketed drugs, Nucleic Acids Research, Volume 46, Issue D1, 4 January 2018, Pages D1137-D1143.

Wishart DS, Feunang YD, Guo AC, Lo EJ, Marcu A, Grant JR, Sajed T, Johnson D, Li C, Sayeeda Z, Assempour N, Iynkkaran I, Liu Y, Maciejewski A, Gale N, Wilson A, Chin L, Cummings R, Le D, Pon A, Knox C, Wilson M. DrugBank 5.0: a major update to the DrugBank database for 2018. Nucleic Acids Res. 2017 Nov 8. doi: 10.1093/nar/gkx1037.

$\mathrm{Wu}, \mathrm{F}$. et al. A new coronavirus associated with human respiratory disease in China. Nature, 222 doi:10.1038/s41586-020-2008-3 (2020).

Xia B, Kang X. Activation and maturation of SARS-CoV main protease. Protein \& cell. 2011;2:282-90.

Yushun Wan, Jian Shang, Rachel Graham, Ralph S. Baric,Fang Li. Receptor Recognition by the Novel Coronavirus from Wuhan: an Analysis Based on Decade-Long Structural Studies of SARS Coronavirus. Journal of virology, 2020. 94(7): e00127-20.

Zhang, L., Lin, D., Sun, X., Curth, U., Drosten, C., Sauerhering, L., Becker, S., Rox, K. and Hilgenfeld, R., 2020. Crystal structure of SARS-CoV-2 main protease provides a basis for design of improved $\alpha$-ketoamide inhibitors. Science.

Zhou, P. et al. A pneumonia outbreak associated with a new coronavirus of probable bat origin. 220 Nature, doi:10.1038/s41586-020-2012-7 (2020).

Zhu, N., Zhang, D., Wang, W., Li, X., Yang, B., Song, J., Zhao, X., Huang, B., Shi, W., Lu, R., Niu, P., Zhan, F., Ma, X., Wang, D., Xu, W., Wu, G., Gao, G. F., \& Tan, W. (2020). A Novel Coronavirus from Patients with Pneumonia in China, 2019. New England Journal of Medicine. https://doi.org/10.1056/NEJMoa2001017 


\section{Supporting Information}

\section{Repurposing of FDA Approved Drugs for the Identification of Potential Inhibitors of SARS-CoV-2 Main Protease}

Table S1: A list of FDA approved drugs and their binding energies with the SARS-CoV-2 main proteas.

\begin{tabular}{|c|c|c|}
\hline S. No. & Repurpose FDA approved Drugs & $\begin{array}{c}\text { Binding affinity } \\
\text { (kcal/mol) }\end{array}$ \\
\hline 1 & Alpha Ketoamide 13b (co-crystallized ligand) & -6.7 \\
\hline 2 & Velpatasvir & -9.1 \\
\hline 3 & Glecaprevir & -9.0 \\
\hline 4 & Grazoprevir & -8.7 \\
\hline 5 & Baloxavir marboxil & -8.4 \\
\hline 6 & Danoprevir & -8.4 \\
\hline 7 & Betulinic Acid & -8.3 \\
\hline 8 & Fostemsavir & -8.2 \\
\hline 9 & Ledipasvir & -8.2 \\
\hline 10 & Paritaprevir & -8.2 \\
\hline 11 & Daclatasvir & -8.1 \\
\hline 12 & Faldaprevir & -8.1 \\
\hline 13 & Lonafarnib & -8.1 \\
\hline 14 & Ravidasvir & -8.1 \\
\hline 15 & Voxilaprevir & -8.1 \\
\hline 16 & Nelfinavir_mesylate & -8.1 \\
\hline 17 & Beclabuvir & -8.0 \\
\hline 18 & Dolutegravir & -8.0 \\
\hline 19 & Saquinavir & -8.0 \\
\hline 20 & Bictegravir & -7.9 \\
\hline 21 & Nelfinavir & -7.9 \\
\hline 22 & Raltegravir_potassium & -7.9 \\
\hline 23 & Tetrandrine & -7.9 \\
\hline 24 & Calanolide_A & -7.8 \\
\hline 25 & Letermovir & -7.8 \\
\hline 26 & Telaprevir & -7.8 \\
\hline
\end{tabular}




\begin{tabular}{|c|c|c|}
\hline 27 & Pimodivir & -7.7 \\
\hline 28 & Pyronaridine & -7.6 \\
\hline 29 & Dasabuvir & -7.5 \\
\hline 30 & Inarigivir & -7.5 \\
\hline 31 & Indinavir & -7.5 \\
\hline 32 & JE_2147 & -7.5 \\
\hline 33 & Presatovir & -7.5 \\
\hline 34 & Elsulfavirine & -7.4 \\
\hline 35 & Tecovirimat & -7.4 \\
\hline 36 & Vedroprevir & -7.4 \\
\hline 37 & Adafosbuvir & -7.4 \\
\hline 38 & Asunaprevir & -7.3 \\
\hline 39 & Delavirdine & -7.3 \\
\hline 41 & Doxycycline & -7.3 \\
\hline 42 & Doravirine & -7.3 \\
\hline 43 & Uprifosbuvir & -7.3 \\
\hline 44 & Artefenomel & -7.2 \\
\hline 45 & Maraviroc & -7.2 \\
\hline 46 & Rupintrivir & -7.2 \\
\hline 47 & Darunavir_ethanolate & -7.1 \\
\hline 48 & Ombitasvir & -7.1 \\
\hline 49 & Rilpivirine & -7.1 \\
\hline 50 & TMC_310911 & -7.1 \\
\hline 51 & Etravirine & \begin{tabular}{|l|}
-7.1 \\
\end{tabular} \\
\hline 52 & Pleconaril & -7.1 \\
\hline 53 & BMS_488043 & -7.0 \\
\hline
\end{tabular}


Table S2: Different types of interactions present between the SARS-CoV-2 main protease and the amino acid residues of selected FDA approved drugs for repurposing. Also, the distances of the amino acid residues from the nearest interaction site of the drugs are reported in $\AA$.

\begin{tabular}{|c|c|c|c|c|c|c|c|c|}
\hline $\begin{array}{l}\text { Name of the } \\
\text { drugs }\end{array}$ & $\begin{array}{l}\text { Hydrogen } \\
\text { bond } \\
\text { interaction }\end{array}$ & $\begin{array}{l}\text { Carbon- } \\
\text { hydrogen } \\
\text { bond } \\
\text { interaction }\end{array}$ & $\begin{array}{l}\pi \text {-sigma } \\
\text { interaction }\end{array}$ & $\begin{array}{l}\pi \text {-sulfur } \\
\text { interaction }\end{array}$ & $\begin{array}{l}\pi \text {-alkyl } \\
\text { interaction }\end{array}$ & $\begin{array}{l}\text { Alkyl } \\
\text { interaction }\end{array}$ & $\begin{array}{l}\pi \text {-anion } \\
\text { interaction }\end{array}$ & $\begin{array}{l}\text { Halogen } \\
\text { interaction }\end{array}$ \\
\hline $\begin{array}{l}\alpha- \\
\text { Ketoamide } \\
13 b\end{array}$ & $\begin{array}{l}\text { Asn142 } \\
(2.38) ; \\
\text { Gly143 } \\
(2.47) ; \\
\text { Cys145 (2.60) }\end{array}$ & $\begin{array}{l}\text { Glu166 } \\
(2.41)\end{array}$ & Met49 (3.65) & Met49 (4.08) & $\begin{array}{l}\text { His41 (5.11) } \\
\text { Cys44 (5.12) } \\
\text { Met165 } \\
(5.04)\end{array}$ & $\begin{array}{l}\text { Met165 } \\
(4.17)\end{array}$ & & \\
\hline Velpatasvir & Gln192(2.35) & $\begin{array}{l}\text { Asn142 } \\
(2.60) \\
\text { Glu166 } \\
(2.83) \\
\end{array}$ & & $\begin{array}{l}\text { Met165 } \\
(5.40)\end{array}$ & $\begin{array}{l}\text { Pro168 (4.70) } \\
\text { Pro168 (4.05) }\end{array}$ & Pro168 (4.99) & & \\
\hline Glecaprevir & $\begin{array}{l}\text { Thr25 (2.71) } \\
\text { His41 }(2.97) \\
\text { Asn142 (2.73) } \\
\text { Cys145 (2.36) }\end{array}$ & His41 (3.74) & & & & Pro168 (4.80) & $\begin{array}{l}\text { Glu166 } \\
(3.23) \\
\text { Glu166 } \\
(3.68) \\
\end{array}$ & $\begin{array}{l}\text { Thr26 } \\
(3.52)\end{array}$ \\
\hline Indinavir & $\begin{array}{l}\text { Thr45 (2.15) } \\
\text { His164 (2.20) } \\
\text { Glu166 (2.26) }\end{array}$ & & $\begin{array}{l}\text { Leu141 } \\
(3.82)\end{array}$ & & $\begin{array}{l}\text { Met165 } \\
(5.13)\end{array}$ & & & \\
\hline
\end{tabular}

